\title{
BMJ Global Health Clubfoot treatment in 2015: a global perspective
}

\author{
Rosalind M Owen, ${ }^{1}$ Beth Capper, ${ }^{1}$ Christopher Lavy ${ }^{2}$
}

To cite: Owen RM, Capper B, Lavy C. Clubfoot treatment in 2015: a global perspective. BMJ Glob Health 2018;3:e000852. doi:10.1136/ bmjgh-2018-000852

Handling editor Seye Abimbola

- Additional material is published online only. To view please visit the journal online (http://dx.doi.org/10.1136/ bmjgh-2018-000852).

Received 27 March 2018 Revised 11 July 2018 Accepted 13 July 2018
Check for updates

(c) Author(s) (or their employer(s)) 2018. Re-use permitted under CC BY-NC. No commercial re-use. See rights and permissions. Published by BMJ.

${ }^{1}$ Global Clubfoot Initative, London, UK

${ }^{2}$ Nuffield Department of Orthopaedics Rheumatology and Musculoskeletal Sciences, University of Oxford, Oxford, UK

\section{Correspondence to}

Rosalind M Owen;

Rosalind.owen@globalclubfoot. org

\section{ABSTRACT}

Introduction Clubfoot affects around 174000 children born annually, with approximately $90 \%$ of these in lowincome and middle-income countries (LMIC). Untreated clubfoot causes life-long impairment, affecting individuals' ability to walk and participate in society. The minimally invasive Ponseti treatment is highly effective and has grown in acceptance globally. The objective of this crosssectional study is to quantify the numbers of countries providing services for clubfoot and children accessing these.

Method In 2015-2016, expected cases of clubfoot were calculated for all countries, using an incidence rate of 1.24/1000 births. Informants were sought from all LMIC, and participants completed a standardised survey about services for clubfoot in their countries in 2015. Data collected were analysed using simple numerical analysis, country coverage levels, trends over time and by income group. Qualitative data were analysed thematically.

Results Responses were received from 55 countries, in which $79 \%$ of all expected cases of clubfoot were born. More than 24000 children with clubfoot were enrolled for Ponseti treatment in 2015. Coverage was less than 25\% in the majority of countries. There were higher levels of response and coverage within the lowest income country group. 31 countries reported a national programme for clubfoot, with the majority provided through public-private partnerships.

Conclusion This is the first study to describe global provision of, and access to, treatment services for children with clubfoot. The numbers of children accessing Ponseti treatment for clubfoot in LMIC has risen steadily since 2005. However, coverage remains low, and we estimate that less than $15 \%$ of children born with clubfoot in LMIC start treatment. More action to promote the rollout of national clubfoot programmes, build capacity for treatment and enable access and adherence to treatment in order to radically increase coverage and effectiveness is essential and urgent in order to prevent permanent disability caused by clubfoot.

\section{BACKGROUND}

Clubfoot, also known as congenital talipes equinovarus affects around 174000 children born each year, with $91 \%$ born in low-income and middle-income countries (LMIC) (Global Clubfoot Initiative (GCI), unpublished data, 2017). Clubfoot can, in up to $95 \%$ of cases, be treated successfully using a largely

\section{Key questions}

What is already known?

- Clubfoot can be treated effectively using the Ponseti method and results in life-long impairment if not treated. An increasing number of countries have accepted the Ponseti method as the gold standard of treatment in the past 2-3 decades and are providing Ponseti treatment for clubfoot.

\section{What are the new findings?}

- More than $90 \%$ of children with clubfoot are born in lower income and middle-income countries (LMICs); an estimated $15 \%$ of these accessed Ponseti treatment in 2015. Approximately 144000 children did not access treatment in 2015.

- In 2005-2015, the number of children accessing treatment in LMIC has increased from an estimated 700 in three countries to more than 24000 in 55 countries. Of those children starting treatment, $53 \%$ remained in treatment at 2 years.

- 31 countries have national programmes for clubfoot, many administered as public private partnerships. Coverage in most countries is less than $25 \%$.

\section{What do the new findings imply?}

- Policy makers, health service providers and other agencies supporting treatment must continue to work together to advocate for, and put in place, treatment services for children with clubfoot.

non-surgical technique: the Ponseti method of treatment. ${ }^{1}$ The Ponseti method is now considered to be the gold standard of treatment in the USA, and its use has spread widely throughout high-income countries (HICs), ${ }^{2-4}$ largely replacing previously used surgical and conservative techniques. It is also more cost-effective, less invasive and has lower risks of complications than surgical treatments. ${ }^{5}$ As such, it is an ideal solution for low-resource settings.

Ponseti treatment is made up of two phases:

1. Corrective phase: correction of deformity by manipulation of the foot and application of plaster casts, changed weekly, followed by a percutaneous Achilles tendon tenotomy in most cases. 
2. Maintenance phase: the feet are held in the corrected position by use of a foot abduction brace (FAB) in order to prevent relapse of deformity. The FAB is worn for $23 / 24$ hours for the first 12 weeks, and then during sleep until 4-5 years old. ${ }^{6}$

Treatment is most effective if initiated early, ideally during infancy, but there are now numerous reports of older children being treated using the Ponseti technique. ${ }^{7}$

Without treatment, clubfoot is a severely disabling condition leading to pain and loss of ability to walk as well as stigma and exclusion from many aspects of daily life such as education and employment. ${ }^{8}$

In recent decades, the Ponseti method has been introduced in a growing number of LMIC. Many countries have established nationally coordinated programmes with the support of local or international non-governmental organisations (NGOs) in order to reach as many children as possible. The authors have completed surveys every 2 years since 2007, including as many treatment providers in LMIC as possible in order to monitor progress in ending disability caused by clubfoot. ${ }^{9}$

A small number of published studies attempt to map global Ponseti treatment provision prior to this study. Shabtai $e t a l^{10}$ document the large increase in published articles concerning the Ponseti method from 1972 to 2014. They performed a literature search that found that 113/193 countries worldwide had documented evidence (published or grey literature) of any Ponseti service provision. The majority of the 80 countries that did not are LMIC. ${ }^{10}$ A study in 2010 on a 10 -country initiative ${ }^{9}$ is one of the first attempts to document global progress in Ponseti provision in 2007-2009. At the time, the 10 countries included, along with Uganda, ${ }^{8}$ were some of the only LMIC where comprehensive coverage was attempted and documented.

This study provides the first comprehensive picture of expected numbers of cases, Ponseti treatment availability, access and coverage globally, including historical trends and analysis by income group.

\section{METHODS}

The authors conducted global surveys of clubfoot services every 2 years since 2007 through GCI, a UK-based charity. In 2016, known contacts were accessed through the GCI contacts database. Three categories of LMIC were defined:

A. Countries with Ponseti services and a contact person known to GCI.

B. Countries with some evidence of Ponseti services (scientific or grey literature) with no contact person known to GCI.

C. Countries with no known Ponseti services or contact persons and no evidence of Ponseti services.

For all category B and C countries, a literature search was carried out in order to assess whether there was any evidence for provision of Ponseti services. The inclusion criteria were:
1. Publication in a peer-reviewed scientific journal documenting Ponseti services.

2. A website or report from an NGO giving evidence of Ponseti services.

Exclusion criteria: If there was evidence of training of a limited number $(<5)$ of healthcare workers from a country in the Ponseti technique, but no evidence of service provision, this was not considered to be evidence for Ponseti provision. Countries were categorised as A, B or $\mathrm{C}$ based on the GCI contacts database and this literature search.

In September-November 2016, GCI requested data from programme coordinators or, in the absence of these, individuals known to be providing Ponseti services in all category A countries (55). For category B countries, we attempted to make contact with either the authors of publications identified or other contacts identified through the literature search. A contact was found for, and data requested from, 21 out of 40 category B countries. There were 46 category $\mathrm{C}$ countries with no evidence of Ponseti treatment.

In total, data were requested from 74 countries across categories A and B for the period January-December 2015. Data were self-reported by programme coordinators or individual practitioners using a standardised data collection form (online supplementary file 1 ).

\section{Data requested included}

- Numbers and locations of clinics providing services for children with clubfoot.

- Numbers and ages of children up to age 15 years enrolling for treatment (defined as: new cases starting treatment using the Ponseti method).

- Number of children starting FABs.

- Number of children completing 2 years of FAB.

- Types of support available for clubfoot services and from which providers.

- Whether there was any form of support within the country from the Ministry of Health $(\mathrm{MoH})$.

Where two or more respondents were working in the same country, they were asked to clarify whether the data they provided was likely to overlap, and any duplicated data were corrected.

Data returned were collated and analysed using simple descriptive statistics to describe results from 2015 and compare with previous years. 'Expected cases' were calculated for every country and were defined as the number of children expected to be born with clubfoot in 2015 , using an incidence rate of $1.24 / 1000$ births $^{11}$ and the country's population and birth rate as reported by the World Bank. ${ }^{12}$ 'Coverage' was defined as the numbers of cases enrolled for treatment under the age of 1 year compared with the expected number of cases born in 2015. Where data on age at enrolment for treatment was not provided, the mean percentage of children enrolled under age 1 year from all countries was applied to provide an estimate of cases under 1 year. Per cent coverage was 
calculated for each country that submitted data using the following formula:

Coverage $=$ cases enrolled under age $1 /$ expected cases [country population/number of births in 2015 per $1000 \times 1.24] \times 100$.

Analysis by income group (low, lower middle or upper middle income) as defined by the World Bank was also performed. ${ }^{13}$ Qualitative data returned in the surveys was analysed thematically, using the questions asked as the themes.

\section{FINDINGS}

The total number of expected cases in all countries in 2015 was 173996. Total expected cases in LMIC in 2015 were $157935(91 \%)$, and total expected cases in HICs were $16061(9 \%)$.

The contacts database and literature review found that, of 141 countries, there were 55 with a known Ponseti treatment provider (category A), 40 with no Ponseti provider known to GCI but evidence of Ponseti services (category B) and 46 with no known Ponseti provider and no evidence of Ponseti provision (category $\mathrm{C}$ ). After contacting all category A countries, and category $\mathrm{B}$ where a contact was identified, there was a response rate of $74 \%$; clubfoot treatment data were submitted from 55 of the 74 countries contacted for information. Survey respondents were a mixture of representatives of international or country level NGOs supporting clubfoot services, and individual clinicians reporting on a single clinic, regional or country level.

In the 55 countries that responded to the survey, there were 124774 expected cases of clubfoot in 2015 , or $79 \%$ of all expected cases of clubfoot in all LMIC (online supplementary file 2).

\section{National level data: number and age of children enrolled}

A total of 24436 children were reported to have enrolled for treatment in the 55 respondent countries. There were 650 clinics providing Ponseti treatment for clubfoot, an average of 11.9 clinics per country. Thirty-eight countries provided information on the ages of children enrolled, as detailed in table 1. Details of all respondent countries are provided in appendix 2 .

Forty-five countries provided information on children receiving their first $\mathrm{FAB}$. A total of 16712 children or $76 \%$ of patients in these countries received their first FAB, a decrease from 2013 when $83 \%$ of children received their first FAB.

Less than half (26) of countries provided data on children completing 2 years of FAB use. In these countries, 8618 children completed 2 years of FAB in 2015 . We

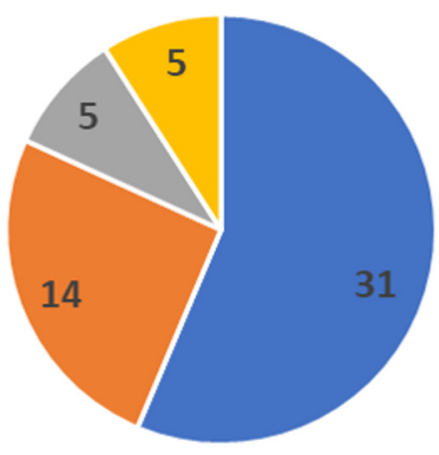

$=0-25 \%=26-50 \%=51-75 \%=76-100 \%$ (includes $>100 \%$ )

Figure 1 Responding countries grouped by coverage level.

analysed the percentage of those completing 2 years of FAB by comparing numbers enrolled in 2013 with 2-year FAB use. Both pieces of data were available from 13 countries; comparison showed that, after 2 years, 4410 of 8262 patients enrolled in 2013 were still using FABs-a 53\% patient retention rate.

\section{Coverage}

A total of 16982 cases enrolled under the age of 1 year, representing coverage within all LMIC of $11 \%$. Coverage within respondent countries was $14 \%$. One of the aims of national programmes for clubfoot is to maximise the number of children born with clubfoot that are able to access treatment. We therefore grouped countries by coverage level (figure 1):

Forty-five countries $(82 \%)$ had coverage of less than $50 \%$, while 10 countries $(18 \%)$ had coverage of more than $50 \%$, including Zimbabwe, Honduras, Dominican Republic, Malawi, Bangladesh, Solomon Islands, Georgia, Namibia, El Salvador and Rwanda.

\section{5 data compared with previous years}

For 14 countries, data were available from 2007 to 2015 . Figure 2 shows the increase in numbers of children enrolled for treatment over 10 years in these 14 countries (Ethiopia, Ghana, Kenya, Malawi, Niger, Rwanda, Zambia, Afghanistan, Bangladesh, India, Laos, Dominican Republic, Haiti and Honduras).

The number of children enrolled for clubfoot treatment in these 14 countries has increased from 379 children in 2005 to 17711 in 2015; a $4573 \%$ increase over 10 years.

Table 1 Age groups (years) of children enrolled in 38 countries

\begin{tabular}{llrrrrrrr}
\hline Age group (years) & $\mathbf{0 - 1}$ & $\mathbf{1 - 2}$ & $\mathbf{2 - 3}$ & $\mathbf{3 - 4}$ & $\mathbf{4 - 5}$ & $\mathbf{5 - 1 0}$ & $\mathbf{1 0 - 1 5}$ & Total \\
\hline Number of children enrolled & 13964 & 2754 & 895 & 397 & 452 & 458 & 141 & 19061 \\
Percentage in age group & 73 & 14 & 5 & 2 & 2 & 2 & 1 & 100 \\
\hline
\end{tabular}




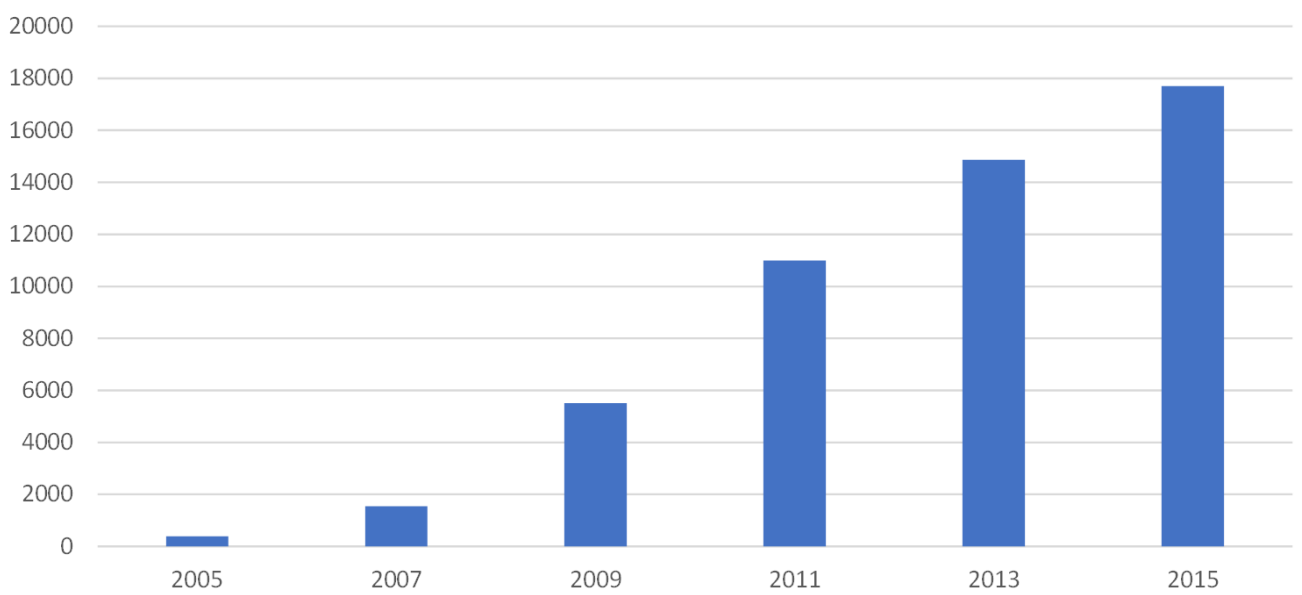

Figure 2 Number of children enrolled in 2005-2015 in 14 LMIC countries.

Key data were compared for all countries from which data were available from 2005, 2007, 2009, 2011 (where available), 2013 and 2015 in order to show change over time, as detailed in the table 2 .

\section{Comparison between country income groups}

Several indicators were compared between country income groups. Countries were divided by income group as defined by the World Bank into low income, lowermiddle income and upper-middle income.

Comparison by country income group shows that the percentage of countries responding to our data request and reporting a national programme was highest in the lowest income countries. Coverage within respondent countries was similar across all groups, but when coverage was calculated for all countries (including non-responders) in each income category, coverage in the lowest income countries was the highest.

\section{Evidence of a national programme}

Of the 55 respondents, 31 reported that there was a national network of clubfoot clinics within their country and 21 reported there was not. The duration of reported national networks ranged from 1 year to 12 years, with a mean duration of 7 years. We did not provide a definition of what a national network was. A number of countries that reported no national network were known to the authors to contain a coordinated network of clinics but with less than full coverage geographically or without formal government collaboration.

\section{Support for clubfoot services}

Thirty-two countries indicated they have government or MoH support for clubfoot treatment, and 11 countries indicated they have no government support. In these countries support was listed from NGOs or in one case (Egypt) 'informal' support is provided through international network of colleagues providing secondhand braces. Table 3 shows the categories and numbers of support provided by governments for clubfoot programmes:

Forty-six countries receive support from non-government agencies, predominantly international and national

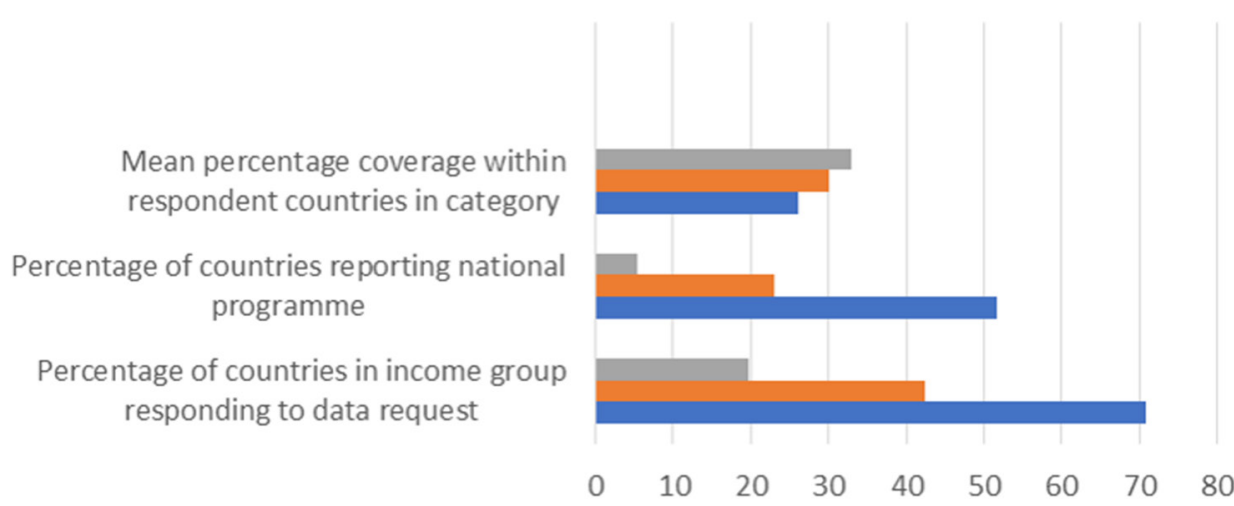

n Upper Middle Income Countries $\mathbf{n}$ Lower Middle Income Countries

- Low Income Countries

Figure 3 Analysis by country income level. 
Table 2 Key data in 2005-2015

\begin{tabular}{|c|c|c|c|c|c|c|}
\hline & 2005 & 2007 & 2009 & 2011 & 2013 & 2015 \\
\hline Number of LMICs providing data & 2 & 4 & 20 & 30 & 39 & 55 \\
\hline Number of children enrolled for Ponseti treatment & 679 & 1163 & 6316 & 12181 & 21515 & 24463 \\
\hline Number of clinics & & & & & 442 & 650 \\
\hline Percentage enrolled at $<1$ year & & & & & 66 & 73 \\
\hline Percentage receiving first FAB & & & & & 83 & 76 \\
\hline Percentage still in treatment at 2 years & & & & & $40-60$ & 53 \\
\hline
\end{tabular}

FAB, foot abduction brace; LMICs, low-income and middle-income countries.

NGOs. Numbers of external supporting agencies ranged from 1 to 7 per country.

Types of NGO support can be roughly divided into five umbrella categories: (1) direct resources (including staffing, equipment, supplies and premises), (2) funding, (3) training, (4) organisational support (including programme management and coordination) and (5) promotion and awareness.

Exact proportions and sources of support could not be ascertained due to the qualitative nature of the data provided, but some clear themes emerged. For most countries, the majority of support for staff and premises comes from $\mathrm{MoH} /$ government with limited reference to this from other sources. Equipment and treatment supplies are reported as coming from both $\mathrm{MoH}$ and NGOs; the balance of this form of support cannot be determined for each country. The majority of support for training comes from NGOs with some detailed from local hospitals or professional bodies. The majority of unspecific 'financial support' is listed as coming from NGOs, with some from Institutional donors and foundations. Limited detail was given about awareness raising and advocacy for clubfoot treatment, but there is evidence that there is a mixture of support for these from MoH and NGOs. A few respondents mentioned support from NGOs for parent advisors.

There are a range of agreements in place with the $\mathrm{MoH}$ and clubfoot programmes, many of which are a publicprivate partnership. Of 45 countries providing responses:

- There is no type of agreement in place with the $\mathrm{MoH}$ in 16 countries $(36 \%)$.

- There is a national, formal agreement in place in 15 countries $(33 \%)$.

Table 3 Support for national clubfoot programmes

\begin{tabular}{ll}
\hline Type of support & $\begin{array}{l}\text { Number of countries } \\
\text { providing this }\end{array}$ \\
\hline Staff & 21 \\
\hline Premises & 13 \\
\hline Equipment and supplies & 12 \\
\hline Training & 3 \\
\hline Awareness and referrals & 5 \\
\hline Other support & 5 \\
\hline
\end{tabular}

- There is a national, informal agreement in place in three countries $(7 \%)$.

- There is a subnational (regional or clinic level), formal agreement in place in five countries (11\%).

- There is a subnational (regional or clinic-level), informal agreement in place in six countries (13\%).

A number of countries submitted incomplete data, defined as such if the respondent notified us that the data were incomplete or there were other potential respondents known to the authors to be providing Ponseti services that did not submit data. These countries include: Egypt, China, Pakistan, Nigeria, Afghanistan, Indonesia, Uganda and Thailand.

\section{DISCUSSION}

More than 24000 children, or $11 \%$ of all children estimated to be born with clubfoot in all LMIC, accessed Ponseti treatment in 2015. Numbers of children accessing treatment have increased steadily since 2005 . The trend documented over time shows a steady increase in the numbers of countries providing data, Ponseti treatment provision and numbers of children accessing Ponseti services. Coverage within the majority of countries remains low, but some countries have achieved coverage of more than $50 \%$, and the factors for success in doing so warrant further investigation. A positive finding was that, of the children enrolled for treatment, $73 \%$ started under age 1 year. However, for older children living with clubfoot for whom treatment using the principles of the Ponseti technique, ${ }^{7}$ clear treatment protocols and services are an area where more research and provision are urgently required.

This report's main focus is on the quantity of Ponseti service provision and access to services, but some inferences may also be drawn about the quality. In 2015, 76\% of children starting treatment received their first FAB, indicative of all of the following:

1. The child remained in treatment through the casting phase.

2. The child's foot was sufficiently corrected to fit into a FAB.

3. A FAB was available.

Current recommendations are for $\mathrm{FAB}$ use to continue until age 4-5 years in order to prevent relapse of the 
clubfoot deformity. ${ }^{14}$ Reported 2-year FAB use indicated that $47 \%$ of patients enrolled in 2013 did not complete 2-year FAB in 2015. This is an area where improvement is needed: at 2 years following initial treatment, the risk of relapse without FAB is high at $30 \%-80 \% .{ }^{14}$ For Ponseti treatment to be most effective, most clinicians recommend starting as soon after birth as possible, and research shows good results in children up to age 2 years. ${ }^{15}$ Age at enrolment gives some indication of the reach of national programmes, access to them and awareness within the general population. It is a positive finding that $87 \%$ of children enrolled for treatment at 2 years of age or less increased from $66 \%$ in 2013. Six per cent (1448) of children enrolled were aged between 3 years and 15 years. More research into the factors affecting adherence with treatment, awareness and treatment seeking and treatment of older children would enable service providers to better meet the needs of the populations served.

Provision within countries showed different patterns of support for elements of treatment. In many countries, government provision such as staff and clinic space was supplemented by NGO support for elements such as staff training and FAB provision. There are only a few countries where there is no support listed outside of government support suggesting that the treatment of clubfoot in LMICs continues to be a collaborative effort between national governments and non-government entities. Comparison by country income groups showed that the greatest percentage of respondents and reported national networks were in the lowest income countries. The authors believe this reflects the greater support for national coordination, monitoring and evaluation in the lowest income countries by NGOs. In countries with more developed health systems, services for clubfoot may be provided as part of a range of paediatric orthopaedic services within national health systems and therefore not coordinated or reported on separately. Anecdotal reports from clinicians within these countries provide verification of this and also indicate that, due to this, there can be problems with provision of FABs where families cannot afford to purchase these if they are not provided by MoH.

This study relied on self-reported data that could not be independently verified. Although the authors made every attempt to identify and include contacts from every LMIC, it was not possible to do so, and this was also reflected in Shabtai et $a l \mathrm{~s}^{10}$ study in 2014, which showed no evidence of Ponseti treatment in 80 countries. It is difficult to find accurate estimates of incidence of clubfoot for individual countries; we therefore used an incidence rate of 1.24/1000 births, based on a systematic review by Smythe $e t a l .{ }^{11}$ However, without more accurate incidence data, any estimates of expected numbers of cases may be flawed. A confounding factor to the growth in number accessing treatment over time documented in this report is that the number of survey respondents increased over time. The authors acknowledge that, since data collection began in 2005, the level of interest in this survey and responses have increased. However, Figure 2 shows that, in 14 countries where data are available for all years of the survey, the trend of growth in access to treatment over time was strong in 2005-2015 and verifying our results to some extent.

Based on the data collected, it is possible to make some estimates about global treatment coverage. This survey is the most comprehensive attempt known to the authors to map provision of, and access to, Ponseti treatment for clubfoot worldwide, using both original data and a literature search. The focus of this study was on LMIC, in which more than $90 \%$ of all expected cases of clubfoot are born, and $79 \%$ of all expected cases of clubfoot in LMIC in 2015 were born in countries that submitted data to this study. A wide breadth of lower and middle-income countries are therefore represented, allowing a global picture of country-level provision to be built up. Regarding depth of data, the authors are aware that, despite our best attempts to gather data from all LMIC, there are some countries where substantial numbers of children are accessing treatment from which we did not get a response, or an incomplete response. Within respondent countries there will also be providers outside the networks that responded to our surveys, such as private clinics. We therefore estimate that a further $20 \%-30 \%$ of children receive Ponseti treatment that are not included in our count. Adding $20 \%$ to the number of children estimated to be enrolled under the age of 1 year (16 981) gives an estimated 20377 children to have started treatment in 2015 , or $12.9 \%$ of all expected cases in LMIC. We therefore estimated that, including cases not counted by our survey, less than $15 \%$ of all children born with clubfoot in LMIC in 2015 started Ponseti treatment.

\section{CONCLUSIONS}

More than 24000 children, or an estimated $11 \%-15 \%$ of all children born with clubfoot in LMIC, accessed Ponseti treatment in 2015. Numbers of children accessing treatment have increased steadily since 2005 , when it is estimated that less than 400 children in LMIC received Ponseti treatment. The 2015 results contained data from 55 countries in which $79 \%$ of all expected cases of clubfoot in LMIC were born. The vast majority of children with clubfoot remain untreated and will therefore experience life-long, limiting disability. The quality of treatment provided, compliance with treatment, coverage levels globally and within countries remain critical areas where improvement is needed. Support for services was delivered through a partnership of NGOs and $\mathrm{MoH}$ in most countries. More action to promote the rollout of national clubfoot programmes, training of clinicians and enable access and adherence to treatment in order to radically increase coverage and effectiveness is essential and urgent in order to prevent permanent disability caused by clubfoot. 
Acknowledgements We would like to thank the GCI Global data working group including Chesca Colloredo Mansfeld, Barbara Rau, Michiel Steenbeek and Saketh Kalathur for assistance with research design. We would also like to thank all who contributed data to the study, including Dr Nariman Abol Oyoun of Assiut University, Egypt.

Contributors All three authors designed the research together. RMO and BC carried out the data collection and initial analysis. The manuscript was reviewed, commented on, revised and approved by all three authors.

Funding The research was funded by Global Clubfoot Initiative.

Competing interests None declared.

Patient consent Not required.

Provenance and peer review Not commissioned; externally peer reviewed.

Data sharing statement An early, incomplete and partial analysis of these same data was presented as an e-poster at the SICOT conference in Rome in 2016, and a small amount of the data were also included in a global clubfoot strategy document, RunFree2030, on the Global Clubfoot Initiative website. There is no other data available from this study, and this research has not been published by, nor is under consideration by any other journal.

Open access This is an open access article distributed in accordance with the Creative Commons Attribution Non Commercial (CC BY-NC 4.0) license, which permits others to distribute, remix, adapt, build upon this work non-commercially, and license their derivative works on different terms, provided the original work is properly cited, appropriate credit is given, any changes made indicated, and the use is non-commercial. See: http://creativecommons.org/licenses/by-nc/4.0/.

\section{REFERENCES}

1. Cooper DM, Dietz FR. Treatment of idiopathic clubfoot. a thirty-year follow-up note. J Bone Joint Surg Am 1995;77:1477-89.

2. Hosseinzadeh P, Kiebzak GM, Dolan L, et al. Management of clubfoot relapses with the ponseti method: results of a survey of the posna members. J Pediatr Orthop 2017.
3. Morcuende JA, Dolan LA, Dietz FR, et al. Radical reduction in the rate of extensive corrective surgery for clubfoot using the Ponset method. Pediatrics 2004;113:376-80.

4. Church C, Coplan JA, Poljak D, et al. A comprehensive outcome comparison of surgical and Ponseti clubfoot treatments with reference to pediatric norms. J Child Orthop 2012;6:51-9.

5. Owen RM, Kembhavi G. A critical review of interventions for clubfoot in low and middle-income countries: effectiveness and contextual influences. J Pediatr Orthop B 2012;21:59-67.

6. Ponseti IV. Treatment of congenital club foot. J Bone Joint Surg Am 1992;74:448-54.

7. Digge V, Desai J, Das S. Expanded age indication for ponset method for correction of congenital idiopathic talipes equinovarus: a systematic review. J Foot Ankle Surg 2018;57:155-8.

8. Pirani S, Naddumba E, Mathias R, et al. Towards effective ponseti clubfoot care: the uganda sustainable clubfoot care project. Clin Orthop Relat Res 2009;467:1154-63.

9. Owen RM, Penny JN, Mayo A, et al. A collaborative public health approach to clubfoot intervention in 10 low-income and middleincome countries: 2-year outcomes and lessons learnt. J Pediatr Orthop B 2012;21:361-5.

10. Shabtai L, Specht SC, Herzenberg JE. Worldwide spread of the Ponseti method for clubfoot. World J Orthop 2014;5:585.

11. Smythe $\mathrm{T}$, Kuper $\mathrm{H}$, Macleod D, et al. Birth prevalence of congenital talipes equinovarus in low- and middle-income countries: a systematic review and meta-analysis. Trop Med Int Health 2017;22:269-85

12. Population, total | Data. https://data.worldbank.org/ (cited 7 Feb 2018).

13. Country WB. World Bank Country and Lending Groups. https:// datahelpdesk.worldbank.org/knowledgebase/articles/906519-worldbank-country-and-lending-groups (cited 2018 Feb 7).

14. Bracing Tips. Ponseti International. http://ponseti.info/bracing-tips. html (cited 2018 Feb 7).

15. Spiegel DA, Shrestha OP, Sitoula P, et al. Ponseti method for untreated idiopathic clubfeet in Nepalese patients from 1 to 6 years of age. Clin Orthop Relat Res 2009;467:1164-70. 